\title{
Effect of Heat-Induced Structural Perturbation of Secondary and Tertiary Structures on the Chaperone Activity of $\alpha$-Crystallin
}

\author{
J iahn-Shing Lee,* Takanori Satoh,† Hiroshi Shinoda,† Tatsuya Samejima,† \\ Shih-Hsiung Wu, $\neq$ and Shyh-Horng Chiouキ'`,1 \\ *Department of Ophthalmol ogy, Chang-Gung Memorial Hospital, §Laboratory of Crystallin Research, Institute of \\ Biochemical Sciences, National Taiwan University, and ¥Institute of Biological Chemistry, P.O. Box 23-106, \\ Academia, Taipei, Taiwan; and †Department of Chemistry, College of Science and Engineering, \\ Aoyama Gakuin University, Tokyo, J apan
}

$\alpha$-Crystallin, a major protein of the lens, is known to have chaperone activity to protect other proteins against thermal aggregation. Heat-induced structural change of $\alpha$-crystallin was previously shown to increase its chaperone activity. In this report, we studied the thermal reversibility of $\alpha$-crystallin and the effect of change in secondary structure on its chaperone function in vitro. The heat-induced conformational changes in the aromatic region of near-UV CD spectra showed only a small degree of reversibility. The structural transitions from 50 to $70^{\circ} \mathrm{C}$ were largely reversible if the incubation time was short. However, the protective ability to inhibit thermal aggregation of alcohol dehydrogenase by $\alpha$-crystallin was essentially similar at 48 and $70^{\circ} \mathrm{C}$. Under long-term heating at high temperatures, there was a time-dependent irreversibility of structural change in $\alpha$-crystallin as revealed by CD spectroscopy. Such denatured $\alpha$-crystallin by long-term heating can still preserve its ability to prevent UV-induced aggregation of $\gamma$-crystallin at room temperature, indicating relatively little effect of heatinduced changes in secondary structure on the chaperone activity of $\alpha$-crystallin. $\odot 1997$ Academic Press

$\alpha$-Crystallin of the ocular lens is a multimeric protein composed of two polypeptides, $\alpha \mathrm{A}$ and $\alpha \mathrm{B}$ subunits, that have considerable sequence homology and are held noncovalently to form aggregates ranging from 700 to more than $1000 \mathrm{kDa}(1)$. This protein is believed to play an important role in the maintenance of lens transparency (2). $\alpha$-Crystallin shows structural and

\footnotetext{
${ }^{1}$ Corresponding address: S.-H. Chiou, Institute of Biological Chemistry, Academia Sinica, P.O. Box 23-106, Taipei, Taiwan. Fax: (886)-2-3635038. E-mail: shchiou@gate.sinica.edu.tw.
}

functional similarities to small heat-shock proteins (3); similarly its expression can also be induced by thermal (4) and osmotic stress (5). In vitro studies of $\alpha$-crystallin also indicate chaperone-like activity of this lens protein in preventing the aggregation of other proteins $(6,7)$. However, the detailed molecular mechanism for its chaperone-like action remains unknown.

Due to its large size and no crystallographic data available, the detailed conformation of $\alpha$-crystallin has not been established and various molecular packing models (8-12) for the association of $\alpha$-crystallin subunits in vivo remain a matter of controversy. In the absence of high-resolution structural data, one way in which information could be obtained is through probing the environments of various amino acids or the location of hydrophobic areas (13). The other way is using circuIar dichroism (CD), Fourier-transform infrared (FT-IR) spectroscopy and/or differential scanning calorimetry (DSC) in conjunction, because these techniques are highly complementary (14). By these methods, it was shown that $\alpha$-crystallin undergoes an irreversible conformational transition with a marked increase in surface hydrophobicity from 38 to $60^{\circ} \mathrm{C}$ (15) together with a loss of its native secondary structure between 50 and $70^{\circ} \mathrm{C}(16)$.

In our previous report (17) using CD spectroscopy, we have also found both secondary and tertiary structural changes in $\alpha$-crystallin under thermal perturbation. Incubation of $\alpha$-crystallin at $50^{\circ} \mathrm{C}$ for $3 \mathrm{~h}$ did not increase its molecular size, whereas $3 \mathrm{~h}$-incubation at $60^{\circ} \mathrm{C}$ changed its Stokes radius from $85 \AA$ to $95 \AA$. A kineticenergy barrier may exist in $\alpha$-crystallin that prevents its denaturation and aggregation at temperatures lower than $50^{\circ} \mathrm{C}$. Under high temperatures, the thermal transition of $\alpha$-crystallin was identified as a conformational change in tertiary structure (partial un- 
folding) and quaternary structure of high-molecularweight (HMW) aggregates, along with a loss of $\beta$-sheet backbone secondary structure (18). The heat-induced structural change in the secondary structure of $\alpha$-crystallin, unlike most of other crystallins, is shown to be largely reversible (19).

On the other hand, it was demonstrated that the ability of $\alpha$-crystallin to protect irradiation-induced aggregation of $\gamma$-crystallin is strongly temperature dependent (20). The short-term preheating of $\alpha$-crystallin showed that the preheated crystallin seemed to have better ability than the native one to prevent dithiothreitol (DTT)-induced aggregation of insulin B chain $(16,18)$, and to inhibit UV-induced aggregation of $\gamma$ crystallin (21) at room temperature. These results suggest that the conformational transitions induced by heating are probably involved in modulating the chaperone activity of $\alpha$-crystallin. However which structural features of $\alpha$-crystallin responsible for the chaperonin function of this crystallin is still not clear. In this report we have further studied the heat-induced denaturation and aggregation of $\alpha$-crystallin by CD spectroscopy to examine the possible effect of heat-induced changes in secondary and tertiary structures on the chaperone activity of $\alpha$-crystallin.

\section{MATERIALS AND METHODS}

I solation of lens crystallins. Lens crystallins were isolated by gelfiltration chromatography as described previously (17). In brief, decapsulated lenses from freshly slaughtered steers (1-2 years ol d) were thoroughly homogenized in an elution buffer containing $0.05 \mathrm{M}$ ammonium bicarbonate, $5 \mathrm{mM}$ EDTA, $0.01 \% \beta$-mercaptoethanol, and $0.02 \%$ sodium azide, $\mathrm{pH} 7.5$. After centrifugation at $27,000 \times \mathrm{g}$ for $30 \mathrm{~min}$, the supernatant (adjusted to $A_{280 \mathrm{~nm}}=100$ ) was applied to a column of TSK HW-55 (S) $(2.5 \times 110 \mathrm{~cm})$ and eluted at $25 \mathrm{ml} / \mathrm{h}$. Five well-resolved peaks were obtained and identified as $\mathrm{HM} \alpha-, \alpha-, \beta \mathrm{H}-$, $\beta \mathrm{L}$ - and $\gamma$-crystallins based on SDS-PAGE. The pooled $\alpha$-crystallin solution was further dialyzed at $0.1 \mathrm{M}$ sodium phosphate $\mathrm{pH} 7.5$ overnight for $C D$ measurements.

Circular dichroism. The CD spectra of $\alpha$-crystallins were measured with a J asco J -600 automatic recording dichrograph with an Adventec LMC-13D temperature-control accessory part. In the thermal perturbation experiments, the average heating rate is $50-60^{\circ} \mathrm{C}$ / $\mathrm{h}$ and after reaching the set temperature, the cooling rate to room temperature is $35-45^{\circ} \mathrm{C} / \mathrm{h}$. Protein concentrations were $0.3 \mathrm{mg} / \mathrm{ml}$ with a $0.1 \mathrm{~cm}$ light path for far-UV CD measurements, and $1.5 \mathrm{mg} /$ $\mathrm{ml}$ with a $1.0 \mathrm{~cm}$ light path for near-UV CD measurements. In both far- and near-UV region, $[\theta]$ is the mean residue ellipticity in degrees. $\mathrm{cm}^{2} /$ decimole based on the mean residue weight of 114 from the known sequence of $\alpha A_{2}$ crystallin chain $(17,22)$.

Assay for chaperone activity of $\alpha$-crystallin under UV-irradiation. Photoaggregation of $\gamma$-crystallin $(0.5 \mathrm{mg} / \mathrm{ml})$ was monitored at $25^{\circ} \mathrm{C}$, in the buffer of TSK gel-filtration column used for crystallin isolation, in the absence or presence of native or preheated $\alpha$-crystallins. The sample solutions were irradiated at $295 \mathrm{~nm}$ with the excitation bandpass of $20 \mathrm{~nm}$ for a fixed time period in a J asco-F P777 spectrofluorometer, and after irradiation the excitation and emission of themonochrometer were set at $600 \mathrm{~nm}$ with a bandpass of $1.5 \mathrm{~nm}$ each to measure the relative scattering as described in the previous report (20). The arbitrary unit of relative scattering was plotted as a function of irradiation or incubation time. The preheated $\alpha$-crystallins

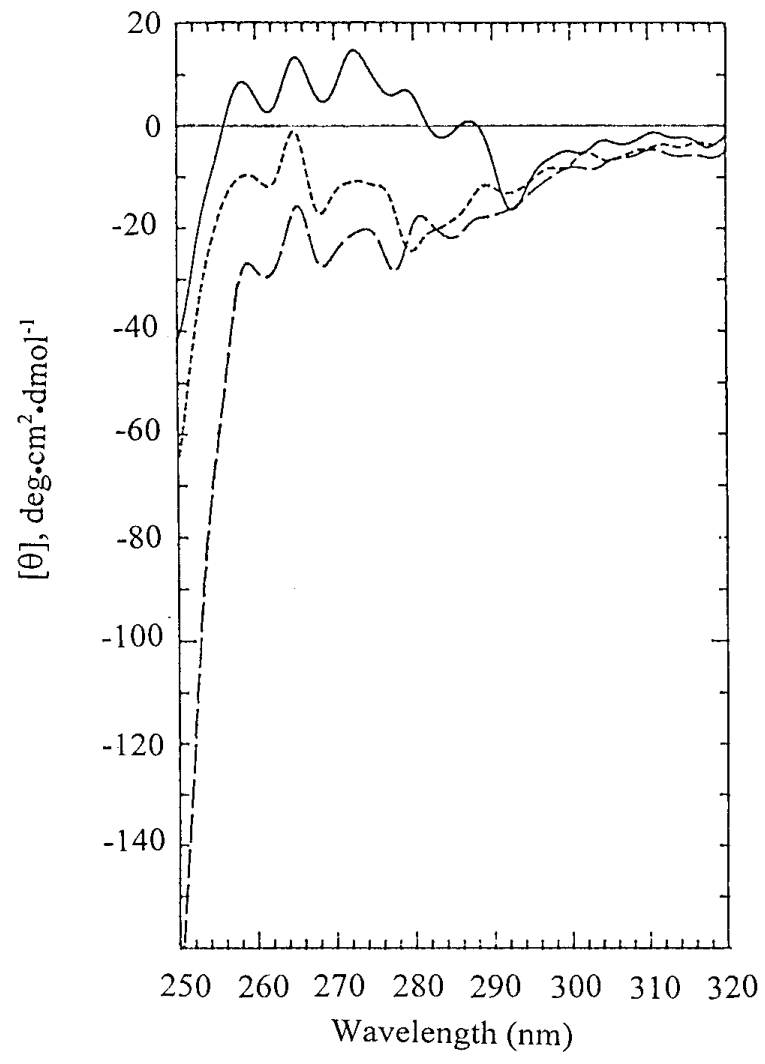

FIG. 1. Near-UV CD spectra of $\alpha$-crystallin at $25^{\circ} \mathrm{C}$ (solid line), $82^{\circ} \mathrm{C}$ (dash line) and $82^{\circ} \mathrm{C}$ sample cooled to $25^{\circ} \mathrm{C}$ (dot line).

were incubated at $82^{\circ} \mathrm{C}$ for $3 \mathrm{~h}$ and cooled down to room temperature overnight.

Assay for chaperone activity of $\alpha$-crystallin under thermal heating. Thermoaggregation of al cohol dehydrogenase $(0.2 \mathrm{mg} / \mathrm{ml})$ was monitored at 48 or $70^{\circ} \mathrm{C}$ respectively for $30 \mathrm{~min}$ in the absence or presence of various amounts of native $\alpha$-crystallins $(0.05-0.8 \mathrm{mg} / \mathrm{ml})$. The relative scattering was monitored at $360 \mathrm{~nm}$ to evaluate thermal aggregation. The turbidity change was expressed by the difference in absorbance between pre and post-incubation. The turbidity change of thermal aggregation of alcohol dehydrogenase in the absence of $\alpha$ crystallin was used as control (100\%). The percentage of turbidity change was plotted against the ratio of $\alpha$-crystallin to alcohol dehydrogenase under 48 and $70^{\circ} \mathrm{C}$ respectively.

\section{RESULTS}

The CD spectra of $\alpha$-crystallin in the near-UV region (Fig. 1) changed minimally in the range of 290 to 320 $\mathrm{nm}$, and gradually shifted from essentially positive to totally negative ellipticity bel ow $290 \mathrm{~nm}$ upon heating the protein solution to $82^{\circ} \mathrm{C}$, indicating a loss of fine structure in some aromatic region of this protein at high temperatures. However, after cooling back to room temperature, most of the near-UV CD spectra could not be reversed. This result is probably related to previous reports $(16,18,20)$ which showed an irreversible temperature-induced quaternary structural change as de- 
tected by hydrophobic probe AN S (1-anilino-8-naphthalene sulfonate) after short-term incubation.

The far-UV CD spectra (Fig. 2A) of native $\alpha$-crystallin at room temperature showed a minimum at around $217 \mathrm{~nm}$, which is indicative of the predominate presence of a high proportion of $\beta$-sheet conformation in this protein (17). As the temperature increased to above $80^{\circ} \mathrm{C}$, there was a drastic shift of $C D$ minimum at $217 \mathrm{~nm}$. The minimum changed to approximately 200-205 $\mathrm{nm}$ at temperatures higher than $85^{\circ} \mathrm{C}(207.2$ $\mathrm{nm}$ at $82^{\circ} \mathrm{C}$ ), indicating a more disordered structure formed at high temperatures $(16,18)$. However after cooling back to room temperature, the shape of far-UV $C D$ spectra is similar to that of the native one, i.e the $C D$ minimum moves back to $217 \mathrm{~nm}$, indicative of a partial recovery of secondary structure.

In Fig. 2B, we shows the change in ellipticity at 205 $\mathrm{nm}$ with respect to temperature graphically. The major transition of secondary structural change is found clearly between 50 and $70^{\circ} \mathrm{C}$. This result is in agreement with the previous report (16). When the temperature returned to room temperature again, the change in ellipticity at $205 \mathrm{~nm}$ in contrast to that at $217 \mathrm{~nm}$ showed a high degree of reversibility. CD ellipticity at $217 \mathrm{~nm}$ showed an increase in band intensity after cooling when compared with the native and unheated sample, which is different from the result of Maiti et al. (19), which showed more or less reversible by heating/ cooling.

Because the major secondary structural change of $\alpha$-crystallin takes place from 50 to $70^{\circ} \mathrm{C}$, we have further examined its chaperone activity to prevent thermal aggregation of alcohol dehydrogenase at 48 and $70^{\circ} \mathrm{C}$, two temperatures cover this transition region. At $48^{\circ} \mathrm{C}$, the backbone conformation of $\alpha$-crystallin did not change while a massive change of secondary structure was noted at $70^{\circ} \mathrm{C}$. Nevertheless it is of interest to find that the protective ability of $\alpha$-crystallin for this enzyme is very similar at these two different temperatures (Fig. 3).

In order to confirm the irreversibility of the heatinduced secondary structural change in $\alpha$-crystallin, we have performed an additional experiment in which aliquots of $\alpha$-crystallin $(0.3 \mathrm{mg} / \mathrm{ml})$ were preheated at different high temperatures for various time intervals and allowed to equilibrate back to room temperature overnight before far-UV CD measurements. As a result, we found a time-dependent secondary structural change of preheated $\alpha$-crystallins. For simplicity, in Fig. 4, we show only the result of $\alpha$-crystallins preheating at $82^{\circ} \mathrm{C} / 15 \mathrm{~min}$ and $82^{\circ} \mathrm{C} / 3 \mathrm{~h}$ as compared with the native one. For $\alpha$-crystallin preheating at $82^{\circ} \mathrm{C} / 3$ $\mathrm{h}$, the far-UV CD spectra of $\alpha$-crystallin showed a large irreversible negative shift at both 217 and $205 \mathrm{~nm}$.

To further assess the effect of heat-induced secondary structural changes on the chaperone activity of $\alpha$ crystallin, we also compare the protective ability be-
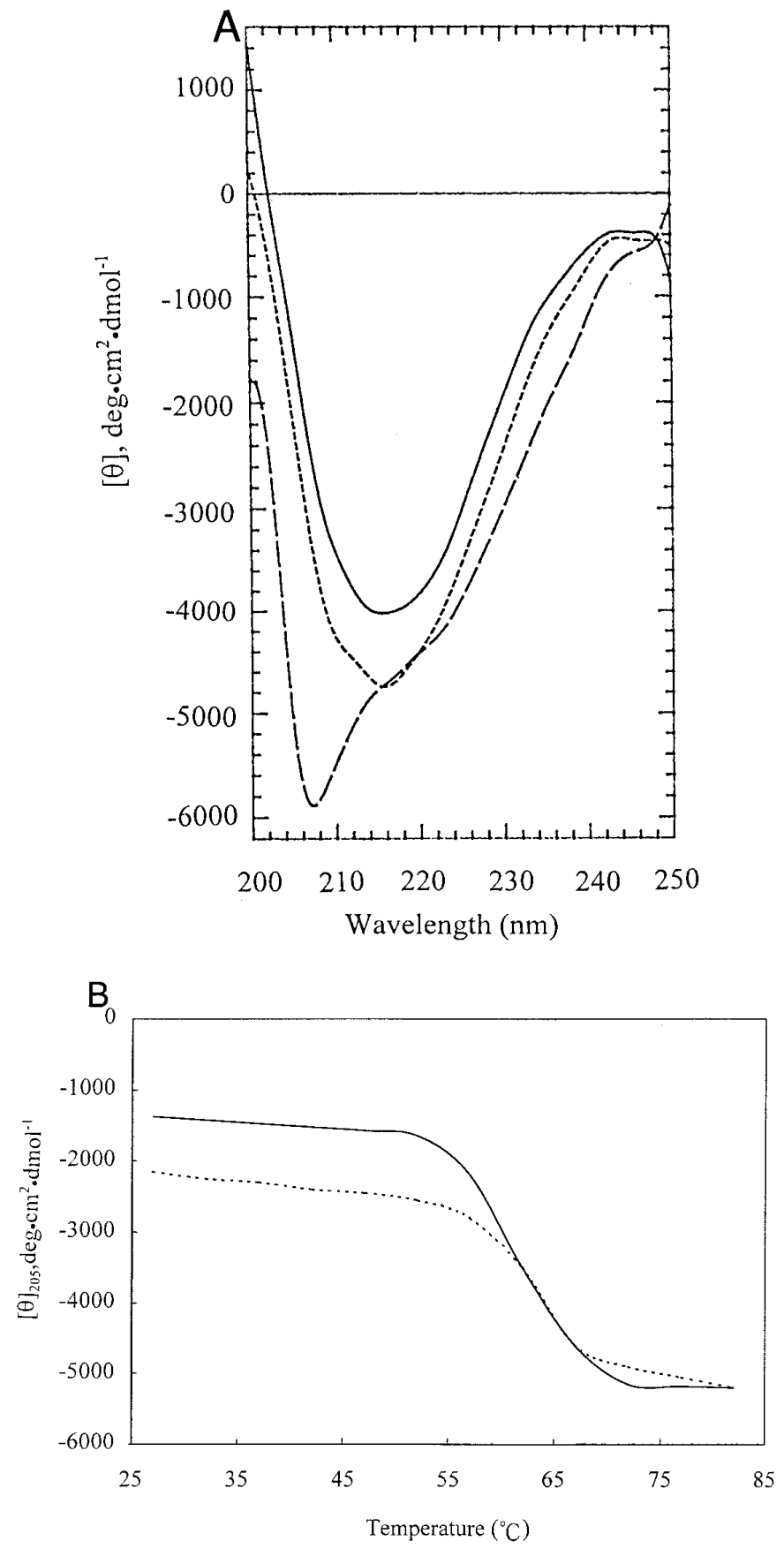

FIG. 2. (A) Far-UV CD spectra of $\alpha$-crystallin at $25^{\circ} \mathrm{C}$ (solid line), $82^{\circ} \mathrm{C}$ (dash line) and $82^{\circ} \mathrm{C}$ sample cooled to $25^{\circ} \mathrm{C}$ (dot line). (B) Change in ellipticity at $205 \mathrm{~nm}$ with respect to temperature. Ellipticities were monitored during the heating cycle (solid line) at a heating rate of $50-60^{\circ} \mathrm{C} / \mathrm{h}$, and after reaching $82^{\circ} \mathrm{C}$ for about $10 \mathrm{~min}$, the cooling cycle (dot line) at a cooling rate of $35-45^{\circ} \mathrm{C} / \mathrm{h}$.

tween the native and $82^{\circ} \mathrm{C} / 3 \mathrm{~h}$ preheated $\alpha$-crystallin for the inhibition of UV-induced aggregation of $\gamma$-crystallin at room temperature. As shown in Fig. 5, photoaggregation of $\gamma$-crystallin leads to aggregation and this process can be suppressed by $\alpha$-crystallin. When 


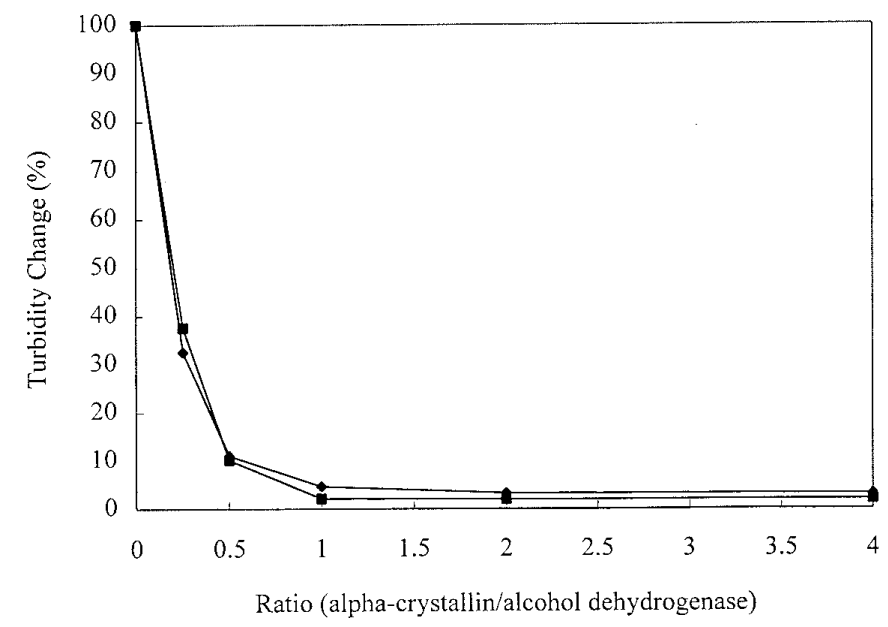

FIG. 3. Thermal aggregation of alcohol dehydrogenase $(0.2 \mathrm{mg} /$ $\mathrm{ml})$ at $48(--)$ and $70^{\circ} \mathrm{C}(-\mathbf{-})$, in the absence and presence of various amounts of $\alpha$-crystallins $(0.05-0.8 \mathrm{mg} / \mathrm{ml})$. The turbidity change was expressed by the difference in absorbance (at $360 \mathrm{~nm}$ ) between pre and post-incubation. The turbidity change of thermal aggregation of alcohol dehydrogenase in the absence of $\alpha$-crystallin was used as control (100\%).

compared with the native one, the $82^{\circ} \mathrm{C} / 3 \mathrm{~h}$ heat-denatured $\alpha$-crystallin, of which the secondary structure has shown a great degree of irreversible change (as in Fig. 4), can still preserve its chaperone activity. This result

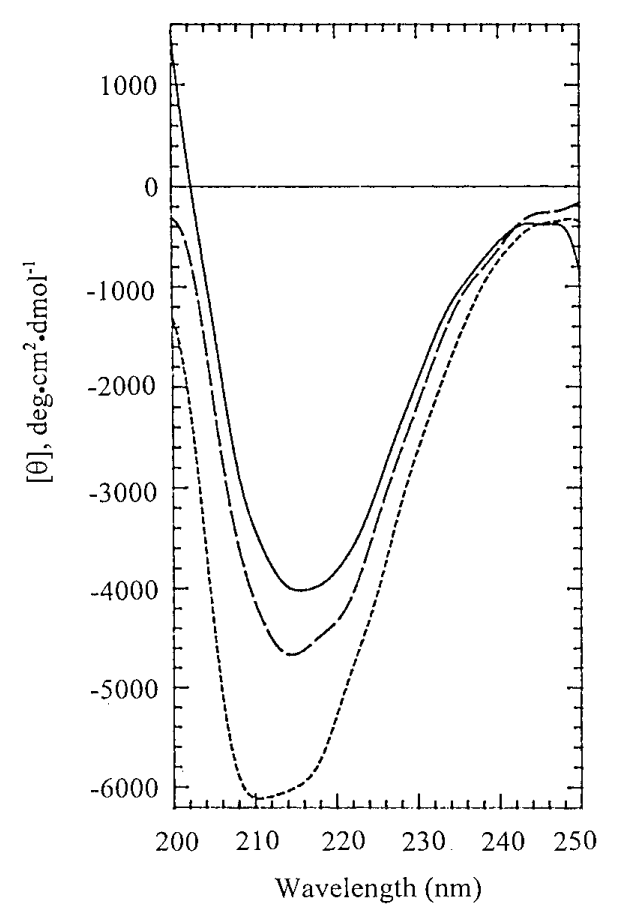

FIG. 4. Far-UV CD spectra of $\alpha$-crystallin, measured at $25^{\circ} \mathrm{C}$ for native state (solid line), preincubation at $82^{\circ} \mathrm{C}$ for $15 \mathrm{~min}$ and cooling down to room temperature overnight (dash line), preincubation at $82^{\circ} \mathrm{C}$ for $3 \mathrm{~h}$ and cooling down to room temperature overnight (dot line).

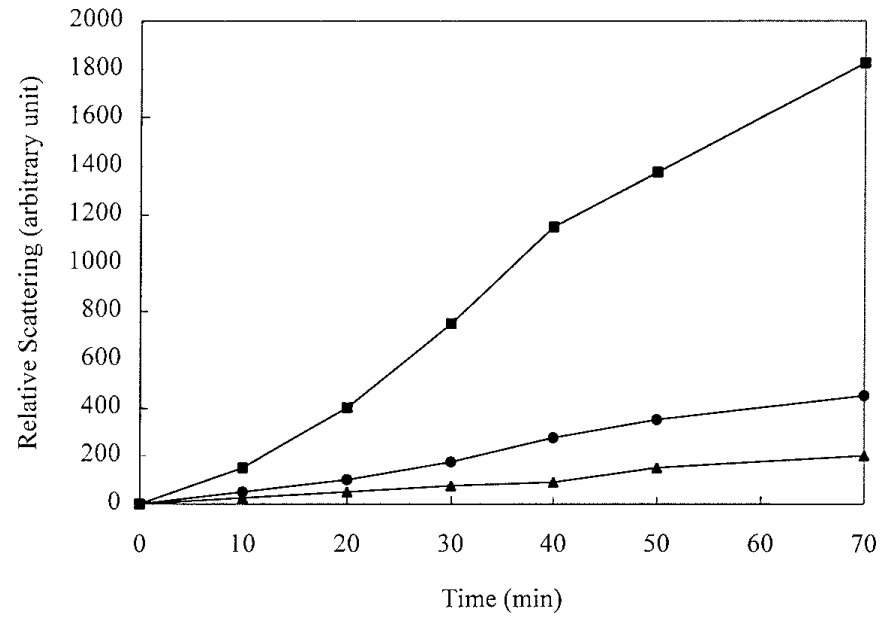

FIG. 5. Photoaggregation of $\gamma$-crystallin irradiated at $295 \mathrm{~nm}$ in the absence $(-\mathbf{-}-)$ or presence of native $(-\bullet-)$ or preheated $(-\boldsymbol{\Delta}-) \alpha$-crystallins. The concentration of $\gamma$-crystallin used in the experiment was $0.5 \mathrm{mg} / \mathrm{ml}$ and that of $\alpha$-crystallin was $0.21 \mathrm{mg} / \mathrm{ml}$. The preheated $\alpha$-crystallin was incubated at $82^{\circ} \mathrm{C}$ for $3 \mathrm{~h}$ and then cooled down to room temperature overnight before the experiment.

is similar to that of short-term preheating experiment in our previous report (21), attesting to the existence of some other factor(s) besides secondary structural changes to account for the chaperone activity of $\alpha$-crystallin under these in vitro experimental conditions.

\section{DISCUSSION}

There is a considerable interest in the functional role of $\alpha$-crystallin, especially after it was shown to have in vitro chaperone activity (6). However, the mechanism of this chaperone action of $\alpha$-crystallin is still not very clear. From some thermodynamic studies (15-19), it was found that this protein is not really "thermostable", and some heat-induced structural transitions may be involved in modulating its chaperone activity $(16,18,20,21)$. Thus the conformation of $\alpha$-crystallin induced by thermal perturbation is of import to elucidate its chaperone mechanism. The information obtained from heat-induced conformational change of $\alpha$-crystallin itself is also important to provide some insights regarding the interactions between $\alpha$-crystallin and its substrates underlying these chaperone reactions during thermal denaturation (23).

A high-resolution calorimetric study of $\alpha$-crystallin (10) showed that it undergoes two thermal transitions, the first between 35 and $51^{\circ} \mathrm{C}$ and the second between 49 and $73^{\circ} \mathrm{C}$, in which only partial reversibility (the second one) was observed. This result is similar to the observation that $\alpha$-crystallin undergoes an irreversible conformational transition with a marked increase in surface hydrophobicity between 38 and $50^{\circ} \mathrm{C}(15)$, and a major loss of its native secondary structure occurring only at temperatures higher than $50^{\circ} \mathrm{C}(16)$. 
The heat-induced tertiary structural change in $\alpha$ crystallin as shown in our near-UV CD spectra was found to be largely irreversible, which is also re flected in the exposure of hydrophobic surface at high temperatures $(15,21)$. E ven at low temperature range $\left(25-37^{\circ} \mathrm{C}\right)$ some subtle structural changes causing partial dissociation of the $\alpha$-crystallin complex have been reported at low temperatures (24). At higher temperatures $\left(>50^{\circ} \mathrm{C}\right), \alpha$-crystallin usually unfolded more quickly and resulted in the formation of $\mathrm{HMW}$ aggregates $(17,18)$.

The previous report (16) indicated that the stability of $\alpha$-crystallin is only comparableto, or even lower than that of other crystallins such as $\beta$ - and $\gamma$-crystallins in terms of their transition midpoints of the heat-induced change in the secondary structure. This protein, unlike most other crystallins, showed a high degree of reversibility in its heat-induced secondary structural change (18). On the other hand, $\gamma$-crystallin became aggregated and precipitated after heating over its transition melting temperature. The reason for this difference is currently not clear. It is possible that such structural transition at high temperatures is not related with the dissociation of native $\alpha$-crystallin complex which is supported by an NMR study (25). Another possibility is that the heat-induced backbone structural change is only a mild denaturation (18) other than a massive loss of secondary structure as observed by FTIR (16), which may make $\alpha$-crystallin less stable due to the presence of deuterium oxide in the studied sample.

Whether the heat-induced secondary structural change is massive or not, the protective ability of $\alpha$ crystallin to inhibit alcohol dehydrogenase was found to be similar at 48 and $70^{\circ} \mathrm{C}$, which lie out of the transition region and may represent two different backbone structural conformations before and after melting transition. Such secondary structural change (massive loss or only $10 \%$ loss of $\beta$-sheet) $(16,18)$ does not appear to affect its chaperone activity. However, whether there is some genuine difference in the heat-induced conformational change between $\alpha$-crystallin alone or $\alpha$-crystallin complex after binding its protective substrates, is now under intensive investigation in our laboratory.

In the present study, the thermodynamic properties of $\alpha$-crystallin indeed show different degree of irreversibility in both its secondary and tertiary structures. The change in the tertiary structure is more pronounced and drastic. The finding that $\alpha$-crystallin undergoes a time-dependent irreversible secondary structural change has also an important implication for studying its effect on the chaperone action of this protein. The $82^{\circ} \mathrm{C} / 3 \mathrm{~h}$ preheated $\alpha$-crystallin showed a slightly higher chaperone activity than the native one, which can be explained by its higher ANS fluorescence (21, data not shown) in spite of its being in a HMW aggregate state by heating $(17,18)$. The results further suggest that there may be a relatively little correlation between heat-induced secondary structural change and the chaperone activity of $\alpha$-crystallin.

It is generally believed that hydrophobic interactions play a major role in the chaperone action of $\alpha$ crystall in and other heat-shock proteins (26). We and other researchers have recently shown that the increase in surface hydrophobicity of $\alpha$-crystallin by short-term heating correlates with its increased chaperone activity $(16,18,20,21)$. It is apparent that the heat-induced secondary structural changes cause little effect on the hydrophobic surface of $\alpha$-crystallin as reflected by ANS binding. This may explain why there is little correlation between the secondary structural change and the chaperone activity of $\alpha$ crystallin. In contrast to other crystallins, the high stability of $\alpha$-crystallin under high temperatures and long-term incubation, is probably related with its unique characteristic of "primary amphiphilicity" (i.e. relatively hydrophobic $\mathrm{N}$-terminal portion and a more polar C-terminal region) in its subunits (16).

$\alpha$-Crystallin has recently been shown not to be lensspecific (3), and it is also not very thermostable in its structure as probed by several physical methods. However it is still in a sense "thermostable" by possessing chaperone-like function in vitro. This fact has probably some significance for its role in the intact lens even though there is virtually no turnover of crystallins during the lifetime of lens devel opment. $\alpha$-Crystallin could preserve or even enhance its chaperonin function despite some irreversible structural change by external stress.

\section{ACKNOWLEDGMENTS}

This work was supported by Academia Sinica and the National Science Council (NSC Grants 83-0418-B-001-020BA, 84-2311-B-001050-BA, and 86-2311-B-002-031-B15), Taipei, Taiwan.

\section{REFERENCES}

1. Harding, J . (1991) in Cataract: Biochemistry, E pidemiology and Pharmacology, Chapman and Hall, London.

2. Groenen, P.J . T. A., Merck, K. B., de J ong, W. W., and Bloemendal, H. (1994) Eur. J . Biochem. 225, 1- 19.

3. Sax, C. M., and Piatigorsky, J . (1994) Adv. Enzymol. 69, 155201.

4. Klemenz, R., Frohli, E., Steiger, R. H., Schafer, R., and Aoyama, A. (1991) Proc. Natl. Acad. Sci. USA 88, 3652- 3656.

5. DasGupta, S., Hohman, T. C., and Carper, D. (1992) Exp. Eye Res. 54, 461- 470.

6. Horwitz, J . (1992) Proc. Natl. Acad. Sci. USA 89, 10449- 10453.

7. Wang, K., and Spector, A. (1994) J. Biol. Chem. 269, 1360113608.

8. Tardieu, A., and Delaye, M. (1988) Ann. Rev. Biophys. Chem. 17, 47- 70 .

9. Augusteyn, R. C., and Kortz, J . F. (1987) FEBS Lett. 222, 1-5.

10. Walsh, M.J ., Sen, A. C., and Chakrabarti, B. (1991) J . Biol. Chem. 266, 20079- 20084.

11. Wistow, G. (1993) Exp. Eye Res. 56, 729- 732. 
12. Carver, J . A., Aquilina, J . A., and Truscott, R. T. W. (1994) Exp. Eye Res. 59, $231-234$.

13. Stevens, A., and Augusteyn, R. C. (1997) Eur. J . Biochem. 243, $792-797$.

14. Surewicz, W. K., Mantsch, H. H., and Chapman, D. (1993) Biochemistry 32, 389-393.

15. Das, K.P., and Surewicz, W. K. (1995) FEBS Lett. 369, 321325.

16. Surewicz, W. K., and Olesen, P. R. (1995) Biochemistry 34, 96559660.

17. Chiou, S.-H., and Azari, P. (1989) J . Protein Chem. 8, 1- 17.

18. Das, B. K., Liang, J . J .-N., and Chakrabarti, B. (1997) Curr. Eye Res. 16, 303- 309.

19. Maiti, M., Kono, M., and Chakrabarti, B. (1988) FEBS Lett. 235, $109-114$.
20. Raman, B., and Rao, C. M. (1994) J . Biol. Chem. 269, 2726427268.

21. Lee, J .-S., Liao, J .-H., Wu, S.-H., and Chiou, S.-H. (1997) J . Protein Chem. 16, 283- 289.

22. van der Ouderaa, F.J., de J ong, W. W., and Bloemendal, H. (1973) Eur. J . Biochem. 39, 207- 222.

23. Das, K. P., Petrash, J. M., and Surewicz, W. K. (1996) J . Biol. Chem. 271, 10449- 10452.

24. Siezen, R. J ., Bindels, J . G., and Hoenders, H. J . (1980) Eur. J . Biochem. 111, 435- 444.

25. Carver, J . A., Aquilina, J . A., and Truscott, R. J . (1993) Biochim. Biophys. Acta 1164, 22- 28.

26. Hayer-Hartl, M. K., Ewbank, J . J ., Creighton, T. E., and Hartle, F. U. (1994) EMBO J . 13, 3192- 3202. 